\title{
Transpulmonary thermodilution during extracorporeal organ support (ECOS): is it worth it?A brief commentary on the effects of the extracorporeal circuit on TPTD-derived parameters
}

\author{
Andrea Minini ${ }^{1,2} \cdot$ Matthias Raes $^{1} \cdot$ Fabio S. Taccone ${ }^{3} \cdot$ Manu L. N. G. Malbrain ${ }^{4,5}$
}

Accepted: 10 February 2021 / Published online: 23 April 2021

(c) The Author(s), under exclusive licence to Springer Nature B.V. 2021

\section{Why transpulmonary thermodilution (TPTD) can have a role during extracorporeal organ support (ECOS)?}

In modern ICUs, critically ill patients with multiple organ dysfunction syndrome (MODS) may be adequately supported by different extracorporeal organ support (ECOS) devices [1]. Improvements in technology have made extracorporeal membrane oxygenation (ECMO) safer and easier to use, allowing potential more widespread application in patients with advanced respiratory failure [2,3]. Similarly, kidney support can be provided by different intermittent and continuous blood purification techniques (Intermittent Hemodialysis, Slow Low-Efficiency Daily Dialysis, Continuous Veno-Venous Hemofiltration, Hemodialysis, or Hemodiafiltration).

Hemodynamic monitoring is essential in these conditions but, while transpulmonary thermodilution (TPTD) methods are well-accepted tools to guide goal direct therapy in critically ill patients, they remain poorly investigated during extracorporeal treatment. The main advantage of transpulmonary thermodilution is the ability to provide a full cardiovascular evaluation $[4,5]$ : continuous measurement of the

Manu L. N. G. Malbrain

manu.malbrain@telenet.be

1 Department of Intensive Care, Universitair Ziekenhuis Brussel (UZ Brussel), Brussels, Belgium

2 Department of Anesthesiology and Intensive Care Medicine, University of Insubria, Varese, Italy

3 Department of Intensive Care, Erasme Hospital, Route de Lennik, Université Libre de Bruxelles (ULB), 808, 1070 Brussels, Belgium

4 Faculty of Engineering, Vrije Universiteit Brussel (VUB), Pleinlaan 2, 1050 Elsene, Belgium

5 International Fluid Academy, Dreef 3, Lovenjoel, Belgium cardiac output (CO) using pulse contour analysis is combined with intermittent volumetric measurement of cardiac preload like global end-diastolic volume (GEDV) and extravascular lung water (EVLW). The consequence of adding an extracorporeal circuit on the accuracy of the TPTD technique is poorly understood and the literature on the topic is scarce (see Table 1). Therefore, we have read with great interest the paper by Herner et al. on the potential loss of indicator into the extracorporeal circuit during veno-venous extracorporeal membrane oxygenation [6].

\section{What were the study findings?}

In the recent study by Herner et al. TPTD-derived parameters before and after initiation of ECMO were compared in 14 ICU-patients with veno-venous ECMO (VV-ECMO) and TPTD-monitoring (PiCCO®, Getinge, Solna, Sweden) [6]. Eight patients had a jugular and six patients had a femoral central venous catheter (CVC). The results of the study showed marked increases in GEDVI $(791 \pm 179$ vs. $\left.974 \pm 384 \mathrm{~mL} / \mathrm{m}^{2} ; \mathrm{p}=0.041\right)$ and EVLWI $(21.3 \pm 9.1 \mathrm{vs}$. $27.7 \pm 11.1 \mathrm{~mL} / \mathrm{kg} ; \mathrm{p}=0.001)$ after the onset of and during ECMO. The increases in GEDVI $\left(378 \pm 247 \mathrm{~mL} / \mathrm{m}^{2}\right.$ vs $36 \pm 210 ; \mathrm{p}=0.02)$ and EVLWI $(10.5 \pm 8.1 \mathrm{~mL} / \mathrm{kg}$ vs. $3.4 \pm 2.4 ; \mathrm{p}=0.06$ ) were substantially more pronounced in patients with femoral compared to jugular indicator injection site [6]. However, cardiac index (CI) and haemodynamic parameters not derived from TPTD, but from pulse contour analysis (systolic and diastolic arterial pressure, stroke volume variation and pulse pressure variation) were not affected by the application of ECMO [6]. 


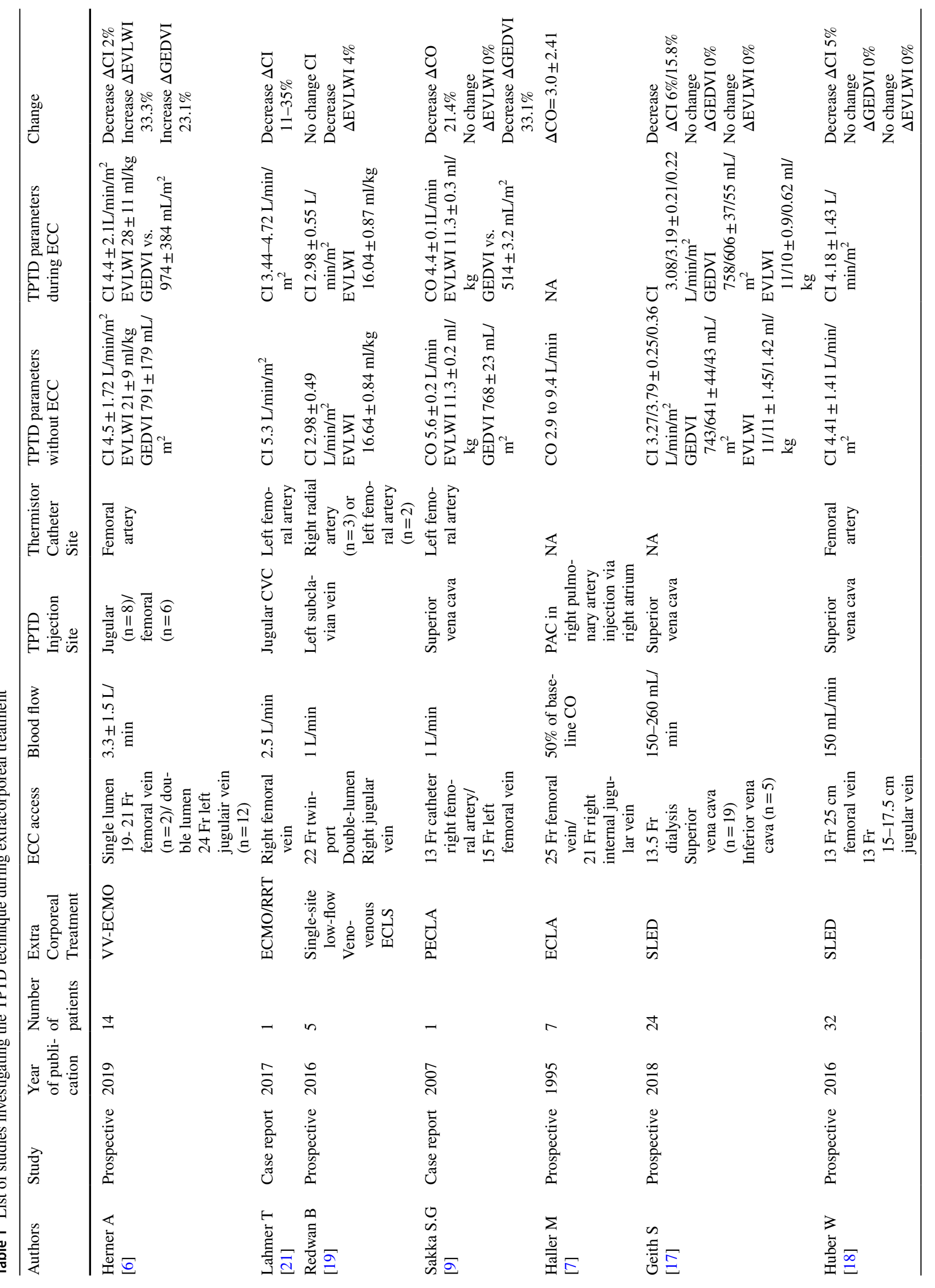




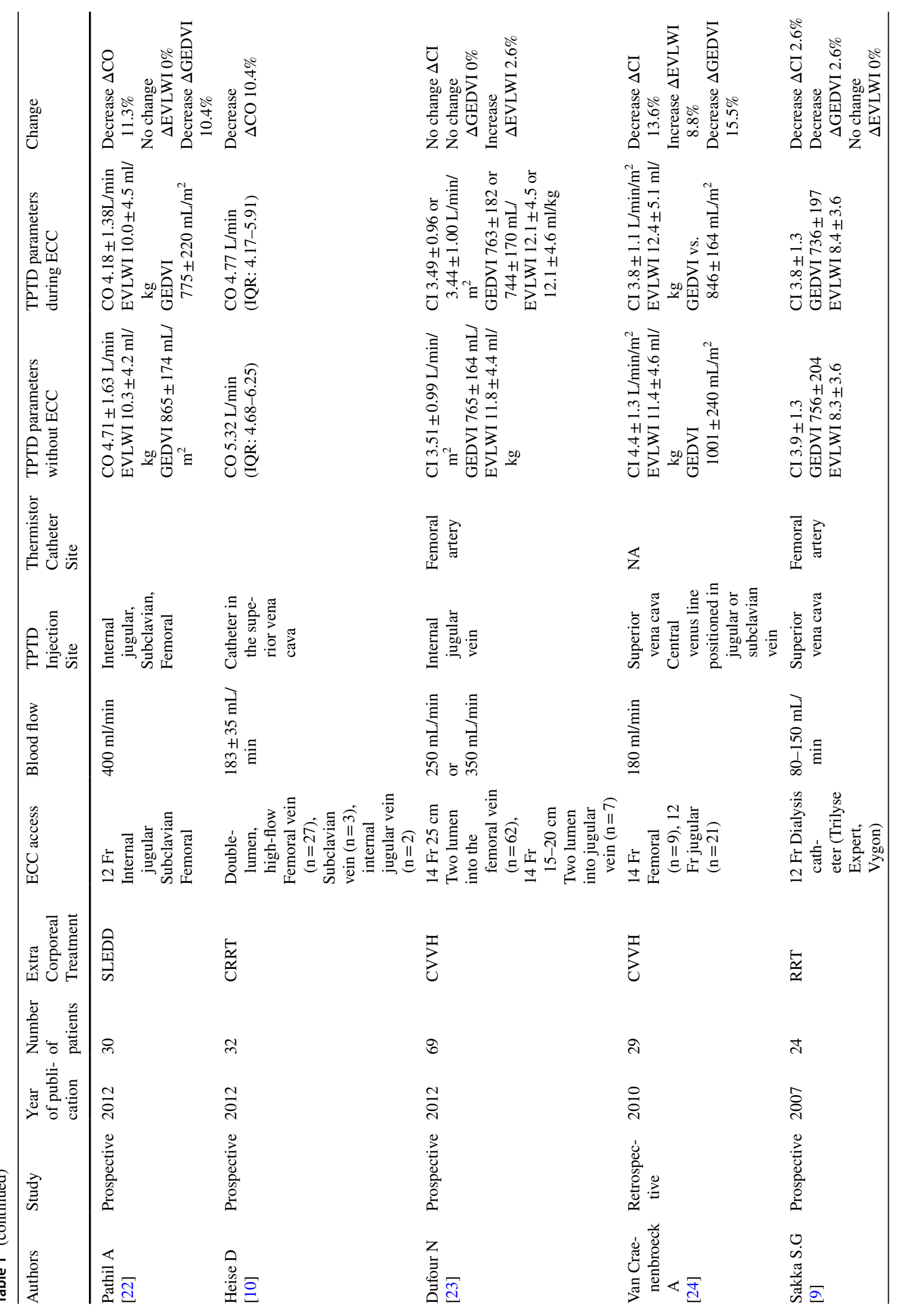




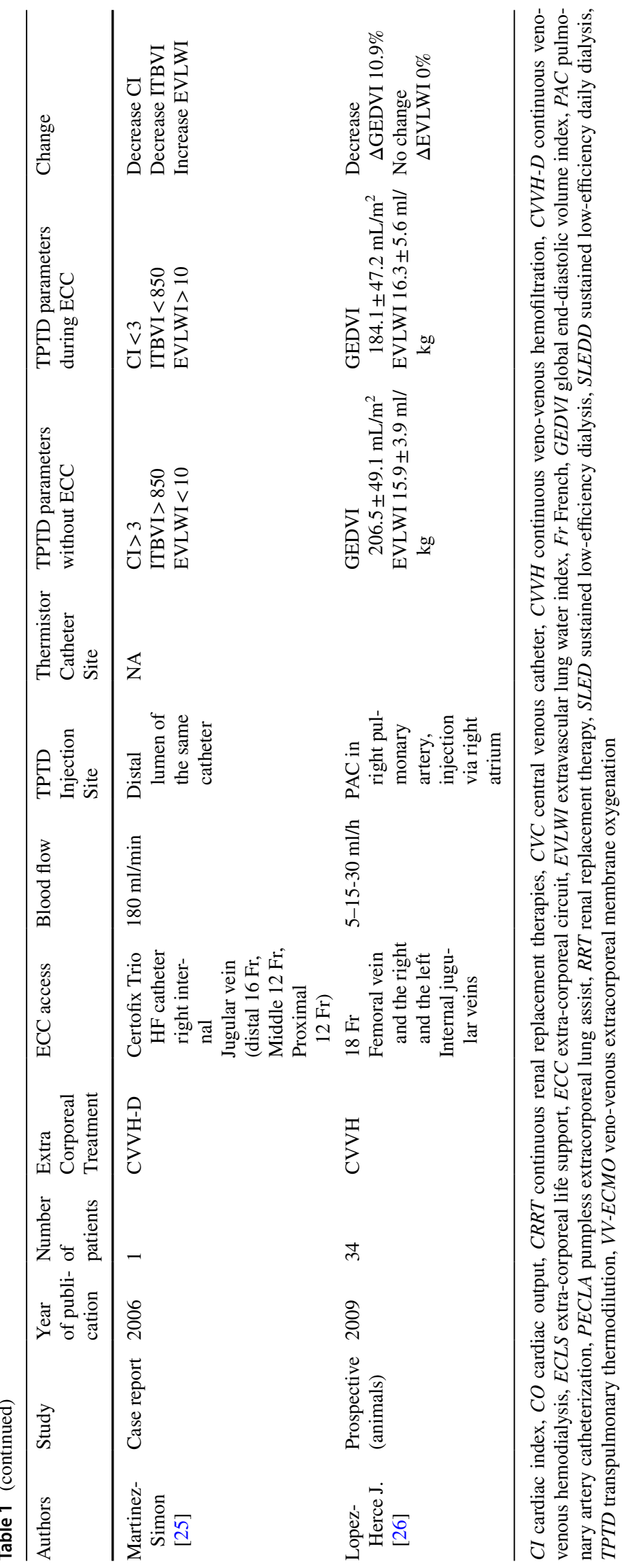




\section{What are the possible pitfalls of TPTD during ECOS?}

First, if we think of the physiology of the extracorporeal circulation, it stands to reason that some part of the thermodilution bolus is going through the extracorporeal circuit, therefore, affecting the values of the parameters measured by TPTD. Haller et al. were the first to test the hypothesis that if the indicator used to determine $\mathrm{CO}$ is injected into the right atrium, adjacent to the drainage cannula, there can be an overestimation due to loss of the indicator (LOI) [7]. To address this issue, they compared the conventional thermodilution $\mathrm{CO}$ determinations with a dye dilution $\mathrm{CO}$ measurement. The results showed an overestimation of the $\mathrm{CO}$ up to a maximum of $300 \%$ (max $10 \mathrm{~L} /$ min higher) with a mean difference of $3.0 \pm 2.41 \mathrm{~L} / \mathrm{min}$. The presence of dye concentration into the extracorporeal circuit confirmed the LOI. As a matter of fact, Sreenan et al. managed to quantify recirculation during VV-ECMO in a rabbit model using a thermodilution technique (Table 1) [8].

Second, the drainage and return cannula may be positioned too close to each other or in such a way that oxygenated blood will preferentially return to the VV-ECMO circuit rather than the right heart circulation, ending in a vicious circle in which ECMO is supporting itself rather than the patient. So, due to the closer proximity of the indicator injection to the femoral ECMO-drainage cannula, the LOI might be more pronounced in case of indicator injection via the femoral central venous catheter compared to jugular indicator injection. In fact, the multivariate analysis performed by Herner et al. showed that femoral indicator injection was independently associated with larger increases in GEDVI $(p=0.004)$ and EVLWI $(p=0.035)$ during ECMO [6]. These findings can be partially explained by the use of the large dual lumen single NovaPort ${ }^{\circledR}$ catheter in this study, which has a greater recirculation rate. Nevertheless, this drawback can be observed also during renal replacement therapy (RRT) and the effect will be more pronounced when the central venous and dialysis catheter are in the femoral and subclavian/internal jugular position respectively, a constellation that is best to be avoided.

Third, when turbulence in flow is present, created for instance by the ECMO device that is pumping blood back into the circulation, the area under the TPTD-curve can be substantially altered and this can affect the mean appearance and mean transit time of the indicator and thus also the different derived parameters. The area under the curve thus will increase because the cold saline needs more time to arrive at the tip of the thermistor through the long arterial line. We believe the same alterations can be produced by any catheter, if TPTD calibration is done during ECOS with a working pump. PiCCO ${ }^{\circledR}$ calibration during extracorporeal support through a central venous catheter may, therefore, produce erroneous measurements. Furthermore, during ECMO, the amount of turbulent flow can increase in proportion to the magnitude of aspiration pressure needed to match the flow rate of the extracorporeal circuit.

Fourth, high-flow ECMO might result in otherwise unexplained alterations of TPTD-derived parameters after the onset of and during ECMO. Observations from the literature review (Table 1) suggest that the influence of the extracorporeal circuit on the reliability of the TPTD-measurements is related to the ratio between the cardiac output and the extracorporeal flow rate. The effects of an extracorporeal circuit are probably more pronounced if $\mathrm{CO}$ is low and the blood flow over the circuit is high (blood flow during continuous veno-venous haemofiltration $(\mathrm{CVVH})$ is generally around $150-180 \mathrm{~mL} / \mathrm{min}$, compared to $450 \mathrm{~mL} / \mathrm{min}$ during dialysis and 3 or more L/min during ECMO). However, some reports suggest that the EVLWI measurement is reliable if extracorporeal blood flow does not exceed $20 \%$ of cardiac output [7,9].

Finally, other aspects that affect TPTD-derived parameters may also play a role such as the filtration rate and the blood temperature. Normally the use of CVVH causes a drop in temperature; stopping the CVVH momentarily may give a rise in central temperature after the inflow of colder fluids coming from the CVVH stops as suggested previously [10]. It also has been suggested to wait with TPTDmeasurements when continuous renal replacement therapy (CRRT) is stopped or started until blood temperature has reached a steady state [11]. We shouldn't forget also the possible influence of mechanical ventilation on the functional haemodynamic indices of fluid responsiveness. Stroke volume variation (SVV) and pulse pressure variation (PPV) ideally require a tidal volume $\geq 8 \mathrm{~mL} \mathrm{~kg}^{-1}$ as a condition for correct interpretation. Although recent data show that the predictive value of functional hemodynamics retains its accurcy even at lower tidal volumes [12], it is appropriate to think that the ultra-protective ventilation strategy during ECMO can disturb proper fluid responsiveness evaluation.

\section{Limitations}

The study by Herner et al. has to be praised to have investigated a topic often underestimated but, to play the devil's advocate, we could argue that the findings raised even more questions. The attractiveness of the TPTD technique lays in the fact that it not only provides a static volumetric preload marker (GEDVI) but also an indicator of extra-vascular fluid overload (EVLWI). However, the cause of the rise of GEDVI in the study is not fully explained. It could be a consequence of reduced heart rate which allows better filling and ultimately better GEDVI or it could be due to fluid 
administration. During the start-up phase of ECMO implementation, these patients usually receive some priming fluid that can be compensated to a certain degree with the blood circulating in the extra-corporeal circuit. Regarding EVLWI, the authors put a lot of emphasis on this parameter but as EVLWI is a marker of pulmonary edema, patients with acute respiratory distress syndrome (ARDS), by definition, should all have an increased EVLWI [13, 14]. Possibly, as suggested by Vasques et al., looking at the carbon dioxide production $\left(\mathrm{VCO}_{2}\right)$ of native lungs compared to the membrane lung may be more interesting from a physiological point of view, especially during VV-ECMO weaning [15].

Furthermore, the usual indication for VV-ECMO is severe respiratory failure due to hypoxemia and/or hypercapnia. In both situations, there is an adrenergic stimulation which increases the cardiac index, in order to compensate for hypoxemia or as an endogenous response to acidemia and hypercapnia. Therefore, after ECMO cannulation, there can usually be a rebound hemodynamic effect observed: heart rate goes down, pulmonary resistance decreases, as well as CI can be reduced. In the study by Heller et al., the authors did not observe a change in CI before and after ECMO $\left(4.4 \pm 1.6\right.$ vs $\left.4.4 \pm 1.2 \mathrm{~L} / \mathrm{min} / \mathrm{m}^{2}\right)$ but it remains unclear why (i.e. therapeutic interventions? fluid administration?). In addition, the fact that they didn't use a "gold standard" (e.g. echo-cardiography) to assess native CI independently from thermodilution is an issue that needs to be taken into account.

Finally, the use of different oxygenators may have biased some results due to the use of different ECC volume and flow patterns.

\section{Conclusion}

Optimized extra-corporeal blood flow adapted to $\mathrm{CO}$ is of paramount importance for effective extra-corporeal support. So, determining the baseline $\mathrm{CO}$ is of utmost importance in patients supported with ECOS, but many common monitoring tools lack validity during ECMO: by taking into account the unique physiology of the ECMO circulation, selected methods can aid in the care of these complex patients [16]. There is evidence to support that TPTD may lose accuracy during ECMO, but we don't have to generalize to all other types of ECOS. Indeed, CRRT (with blood flows below $200 \mathrm{ml} / \mathrm{min}$ ) seems to have no major clinical impact with only a small observed decrease in CI and either no effect or slight changes in GEDVI and EVLWI (see Table 1). Furthermore, there is some evidence that TPTD is feasible during low-flow (up to $500 \mathrm{~mL} / \mathrm{min}$ ) extracorporeal organ support $[17,18]$. Also, VV-ECMO with low flows seems to maintain the accuracy of TPTD-derived parameters. In a group of five patients on low-flow $(0.5,1$, and $1.5 \mathrm{l} / \mathrm{min})$,
VV-ECMO for hypercapnic respiratory failure, TPTD (with injection of cold isotonic saline into the left subclavian vein and dual-lumen ECMO cannula in the right internal jugular vein) provided estimates of $\mathrm{CO}$ that were similar to those measured by pulse contour analysis [19].

Undoubtedly, alternatives to TPTD should be considered during extracorporeal treatment, especially when blood flows are high and CI is low. Point of care ultrasound could play a significant role in monitoring both global and regional perfusion [20]. A proper monitoring tool will allow us to optimize goal-directed therapy, with rigorous control of fluid balance, in order to lower the risk of further organ failure or poor outcome in these patients.

Acknowledgements MLNGM is co-founder and former President of WSACS (The Abdominal Compartment Society, http://www.wsacs. org) and current Treasurer, he is also member of the medical advisory Board of Pulsion Medical Systems (part of Getinge group) and Serenno Medical, and consults for Baxter, BD, BBraun, ConvaTec, Acelity, Spiegelberg, and Holtech Medical. He is co-founder of the International Fluid Academy (IFA). The IFA is integrated within the not-forprofit charitable organization iMERiT, International Medical Education and Research Initiative, under Belgian law. The other authors have no potential conflicts of interest in relation to the contents of this paper.

\section{Compliance with ethical standards}

Ethical Approval Not required.

\section{References}

1. Ronco C, Ricci Z, Husain-Syed F. From multiple organ support therapy to extracorporeal organ support in critically Ill patients. Blood Purif. 2019;48(2):99-105.

2. Fan E, Gattinoni L, Combes A, Schmidt M, Peek G, Brodie D, et al. Venovenous extracorporeal membrane oxygenation for acute respiratory failure : A clinical review from an international group of experts. Intensive Care Med. 2016;42(5):712-24.

3. Karagiannidis C, Brodie D, Strassmann S, Stoelben E, Philipp A, Bein T, et al. Extracorporeal membrane oxygenation: evolving epidemiology and mortality. Intensive Care Med. 2016;42(5):889-96.

4. Hofkens PJ, Verrijcken A, Merveille K, Neirynck S, Van Regenmortel N, De Laet I, et al. Common pitfalls and tips and tricks to get the most out of your transpulmonarythermodilution device: results of a survey and state-of-the-art review. Anaesthesiol Intensive Ther. 2015;47(2):89-116.

5. Litton E, Morgan M. ThePiCCO monitor: a review. Anaesth Intensive Care. 2012;40(3):393-409.

6. Herner A, Lahmer T, Mayr U, Rasch S, Schneider J, Schmid RM, et al. Transpulmonary thermodilution before and during veno-venous extra-corporeal membrane oxygenation ECMO: an observational study on a potential loss of indicator into the extra-corporeal circuit. J Clin Monit Comput. 2020;34(5):923-36.

7. Haller M, Zöllner C, Manert W, Briegel J, Kilger E, Polasek J, et al. Thermodilution cardiac output may be incorrect in patients 
on venovenous extracorporeal lung assist. Am J Respir Crit Care Med. 1995;152(6 Pt 1):1812-7.

8. Sreenan C, Osiovich H, Cheung PY, Lemke RP. Quantification of recirculation by thermodilution during venovenous extracorporeal membrane oxygenation. J Pediatr Surg. 2000;35(10):1411-4.

9. Sakka SG, Hanusch T, Thuemer O, Wegscheider K. The influence of venovenous renal replacement therapy on measurements by the transpulmonarythermodilution technique. Anesth Analg. 2007;105(4):1079-82.

10. Heise D, Faulstich M, Morer O, Brauer A, Quintel M. Influence of continuous renal replacement therapy on cardiac output measurement using thermodilution techniques. Minerva Anestesiol. 2012;78(3):315-21.

11. Mross M, Sakka SG. Influence of different blood flows through a pumpless lung assist system on transpulmonarythermodilutionderived variables. Intensive Care Med. 2010;36(2):369-70.

12. Freitas FG, Bafi AT, Nascente AP, Assuncao M, Mazza B, Azevedo LC, et al. Predictive value of pulse pressure variation for fluid responsiveness in septic patients using lung-protective ventilation strategies. Br J Anaesth. 2013;110(3):402-8.

13. Huber W, Hollthaler J, Schuster T, Umgelter A, Franzen M, Saugel B, et al. Association between different indexations of extravascular lung water (EVLW) and $\mathrm{PaO} 2 / \mathrm{FiO} 2$ : a two-center study in 231 patients. PLoS ONE. 2014;9(8):e103854.

14. Tagami T, Ong MEH. Extravascular lung water measurements in acute respiratory distress syndrome: why, how, and when? Curr Opin Crit Care. 2018;24(3):209-15.

15. Vasques F, Romitti F, Gattinoni L, Camporota L. How I wean patients from veno-venous extra-corporeal membrane oxygenation. Crit Care. 2019;23:316.

16. Krishnan S, Schmidt GA. Hemodynamic monitoring in the extracorporeal membrane oxygenation patient. Curr Opin Crit Care. 2019;25(3):285-91.

17. Geith S, Stecher L, Rabe C, Sack S, Eyer F. Sustained low efficiency dialysis should not be interrupted for performing transpulmonarythermodilution measurements. Ann Intensive Care. 2018;8(1):113.

18. Huber W, Fuchs S, Minning A, Küchle C, Braun M, Beitz A, et al. Transpulmonarythermodilution (TPTD) before, during and after Sustained Low Efficiency Dialysis (SLED). A Prospective
Study on Feasibility of TPTD and Prediction of Successful Fluid Removal. PLoS ONE. 2016;11(4):e0153430.

19. Redwan B, Ziegeler S, Freermann S, Meemann T, Semik M, Dickgerber N, et al. Single-site low-flow veno-venous extracorporeal lung support does not influence hemodynamic monitoring by transpulmonarythermodilution. Asaio j. 2016;62(4):454-7.

20. Bond O, Pozzebon S, Franchi F, Zama Cavicchi F, Creteur J, Vincent JL, et al. Comparison of estimation of cardiac output using an uncalibrated pulse contour method and echocardiography during veno-venous extracorporeal membrane oxygenation. Perfusion. 2019:267659119883204.

21. Lahmer T, Mayr U, Rasch S, BatresBaires G, Schmid RM, Huber W. In-parallel connected intermittent hemodialysis through ECMO does not affect hemodynamic parameters derived from transpulmonarythermodilution. Perfusion. 2017;32(8):702-5.

22. Pathil A, Stremmel W, Schwenger V, Eisenbach C. The influence of haemodialysis on haemodynamic measurements using transpulmonarythermodilution in patients with septic shock: an observational study. Eur J Anaesthesiol. 2013;30(1):16-20.

23. Dufour N, Delville M, Teboul JL, Camous L, Favier du Noyer A, Richard C, et al. Transpulmonarythermodilution measurements are not affected by continuous veno-venous hemofiltration at high blood pump flow. Intensive Care Med. 2012;38(7):1162-8.

24. Van Craenenbroeck A, Van Ingelgem A, Palmers P-J, Cordemans C, Van Hootegem A, Van Regenmortel N, et al. Influence of continuous venovenous hemofiltration $(\mathrm{CVVH})$ and catheter position on transpulmonarythermodilution derived parameters with Picco. Intensive Care Med. 2010;36:S294.

25. Martínez-Simón A, Monedero P, Cacho-Asenjo E. Erroneous measurement of haemodynamic parameters by PiCCO monitor in a critically ill patient with renal replacement therapy: a case report. Critical care. 2006;10(2):410.

26. López-Herce J, Rupérez M, Sánchez C, García C, García E. Effects of initiation of continuous renal replacement therapy on hemodynamics in a pediatric animal model. Ren Fail. 2006;28(2):171-6.

Publisher's Note Springer Nature remains neutral with regard to jurisdictional claims in published maps and institutional affiliations. 